\title{
Questionnaire Survey for Assessing the Present Condition of Children with Eating Disorders in Japanese Schools
}

Kaoru Seike ${ }^{1,2^{*}}$, Michiko Nakazato ${ }^{1,2}$, Hisashi Hanazawa ${ }^{2,3}$, Toshiyuki Ohtani ${ }^{2,4}$, Tomihisa Niitsu $^{5}$, Shinichi Ishikawa ${ }^{6}$, Atsuko Ayabe ${ }^{7}$, Ryoko Otani $^{7}$, Kentaro Kawabe $^{8}$, Fumie Horiuchi ${ }^{8}$, Shizuo Takamiya ${ }^{6}$ and Ryoichi Sakuta ${ }^{7}$

${ }^{1}$ United Graduate School of Child Development, Osaka University, Japan

${ }^{2}$ Research Center for Child Mental Development, Chiba University, Chiba, Japan

${ }^{3}$ Faculty of Education, Chiba University, Chiba, Japan

${ }^{4}$ Safety and Health Organization, Chiba University, Chiba, Japan

${ }^{5}$ Department of Psychiatry, Graduate School of Medicine, Chiba University, Chiba, Japan

${ }^{6}$ Department of Psychiatry, Nishi-Kobe Medical Center, Kobe, Japan

${ }^{7}$ Center for Child Development and Psychosomatic Medicine, Dokkyo Medical University Koshigaya Hospital, Koshigaya, Japan

${ }^{8}$ Department of Neuropsychiatry, Ehime University Graduate School of Medicine and Center for Child Health, Behavior and Development, Ehime University Hospital, Toon City, Ehime, Japan

"Corresponding author: Kaoru Seike, United Graduate School of Child Development, Osaka University, Japan, Tel: 81-43-226-2975; E-mail: funfunfun@sgr.e-catv.ne.jp Rec date: Mar 04, 2016; Acc date: Mar 09, 2016; Pub date: Mar 11, 2016

Copyright: $\odot 2016$ Seike K, et al. This is an open-access article distributed under the terms of the Creative Commons Attribution License, which permits unrestricted use, distribution, and reproduction in any medium, provided the original author and source are credited.

\begin{abstract}
Background: As the proportion of teens in the onset ages has increased, it has become important to detect eating disorder (ED) students early in school and clarify the way of support. Though epidemiological surveys of Yogo teachers have been conducted to inquire the number of ED students, none of these were based on DSM-5. Thus, we conducted a wide area survey in Japan for proposing a better framework of support for Yogo teachers in the early detection/support of ED students.
\end{abstract}

Methods: A questionnaire survey organized by ED type (based on DSM-5) was administered to Yogo teachers working at elementary/junior high/senior high/special needs schools in four prefectures of Japan in 2015, and 1886 responses were obtained. Based on the results, the encounter rates (the proportions of Yogo teachers who had met ED students) were calculated, and factors affecting them were examined by logistic regression analysis.

Results: The order of the encounter rates of the ED type was Anorexia Nervosa (AN)>Bulimia Nervosa $(B N)>$ Avoidant/Restrictive Food Intake Disorder (ARFID)>Binge Eating Disorder (BED)>others. The factors significantly affecting the rates were location, school type, number of students, experience years, and AN knowledge for AN, school type, experience years, BN knowledge for BN, location, school type, experience years, BED knowledge for BED, location, experience years, ARFID knowledge for ARFID and school type, experience years, Others knowledge for Others.

Conclusions: Since the encounter rate of AN was highest, providing support for AN would be effective. Moreover, a factor affecting the rate of all ED types was the ED knowledge. Senior high schools had the highest rates for $A N, B N$ and $B E D$, and special needs schools had the highest for others. These findings imply that for detecting/supporting ED students early, it is necessary to offer knowledge of the corresponding ED type to Yogo teachers at the corresponding school type.

Keywords: Eating disorder; Yogo teacher; Surveillance; Support; DSM-5

\section{Abbreviations}

ED: Eating Disorder; AN: Anorexia Nervosa; BN: Bulimia Nervosa; BED: Binge Eating Disorder; ARFID: Avoidant/Restrictive Food Intake Disorder; Others: Pica, rumination disorder, etc.; CI: Confidence Interval; EDNOS: Eating Disorder Not Otherwise Specified.

\section{Introduction}

The lowering of the age of onset and chronicity have been found to be key problems related to eating disorders (ED) in recent years [1,2].
Children with EDs are likely to fall into physical crises and develop growth disorders [3]. It is necessary to diagnose them and intervene beginning at an early stage. Children with EDs, especially Anorexia Nervosa (AN), strongly resist treatment, and often do not visit medical institutions. Therefore, actual condition surveys are believed to be necessary [4]. Moreover, it is important to detect students suspected of having EDs early and to clarify the way they are supported in school, since the proportion of teens in the estimated onset age range of ED has increased year by year $[5,6]$.

It is important to determine how many ED students are present in school for the purpose of early detection. Although school physicians do medical check-ups and recommend that students suspected of having EDs visit medical institutions based on a Japanese law, half to 
Page 2 of 7

one-third of AN students do not follow the advice [7]. Therefore, school staff members have been a focus of attention in recent years, as they are in the best position to identify the early warning signs of EDs and to support ED students [8]. Yogo teachers are unique teachers in Japan. They not only take care of students like school nurses, but also are in charge of health education. They stay at school on weekdays, teach courses of adolescent health and contact with parents. They watch both mental and physical health of students through body measurements, daily health observation and information from other teachers or students.

As they are not nurses, only some of them have nurse-licenses [7]. 1 They play roles of gatekeepers screening out students suspicious of having diseases and refer them to school physicians. Actually, epidemiological surveys of Yogo teachers have achieved fruitful results in recent years [9-16]. Many of them reported the lowering of the age of onset of EDs. For example, [12] reported the existence of a third grader with $\mathrm{AN}$, and [14] reported that $\mathrm{AN}$ was more prevalent among "younger students (elementary school students)" than previously thought. While many epidemiological actual condition surveys of AN were conducted, surveys of other ED types have rarely been done in Japan [13] (although some have been done outside Japan [17-21]). Moreover, all of those Japanese studies were based on the diagnosis criteria in DSM-IV $[2,7,9-16]$, and no survey by ED type has been done based on the new diagnostic criteria in DSM-5 [The ED types described in DSM-5 are Anorexia Nervosa (AN), Bulimia Nervosa (BN), Binge Eating Disorder (BED), Avoidant/Restrictive Food Intake Disorder (ARFID), and other types of EDs such as rumination disorder or pica (Others)].

The American Psychiatric Association revised the DSM diagnosis criteria in 2013, and "Eating Disorders" and "Feeding and Eating Disorders in Infancy or Early Childhood" in DSM-IV were integrated into a new diagnosis category, "Eating Behavior Disorders and Eating Disorders." This change can be attributed to the fact that there was no need to separate infancy or early childhood from other ages, as it was widely recognized that EDs, previously believed to emerge mainly in infancy or early childhood, actually emerged at other ages too [22]. In addition, 1 the prevalence rates of EDs were reported to be higher in DSM-5 than DSM-IV-TR, for DSM-5 has an increased number of symptom names and more flexible diagnostic criteria [19,23]. These facts mean that a new survey by ED type based on DSM- 5 is necessary.

Our previous study surveyed the encounter rate effective for supporting Yogo teachers in the early detection/support of ED students. However, the results of that study could be biased since the survey subjects were limited to Chiba, a prefecture of Japan. Moreover, our results were problematic in that the confidence intervals of the estimated proportions were long, owing to the small sample sizes for special needs schools and others. (Special needs schools are institutes for educating children flexibly according to their conditions of dysfunction.).

In order to solve these problems, we chose samples from a wider area of Japan and surveyed the encounter rate by ED type. In addition, we surveyed the factors that could affect the rates in order to enhance the effectiveness of the support for children with EDs. In other words, our objectives were to conduct a questionnaire survey of Yogo teachers in four prefectures, calculate the encounter rate by ED type (based on DSM-5), and examine the relations between the rates and location, school type, number of students, years of experience as a Yogo teacher, nurse experience, and ED knowledge.

\section{Methods}

\section{Sample selection}

The survey subjects were Yogo teachers working at elementary schools, junior high schools, senior high schools, and special needs schools in Chiba prefecture, Saitama prefecture, Hyogo prefecture, and Ehime prefecture.

\section{Demographics of prefectures}

Chiba, Saitama, Hyogo and Ehime are administrative divisions (prefectures) of Japan. Chiba and Saitama are within the Tokyo metropolitan area and are classified as "urban." Hyogo is located in the Osaka metropolitan area and is "semi-urban." Ehime is located to the west of Osaka and is "rural" (Figure 1). (We classified an area with a population density of more than 1000 people per square meter as "urban", 500 1000 as "semi-urban", and less than 500 as "rural.").

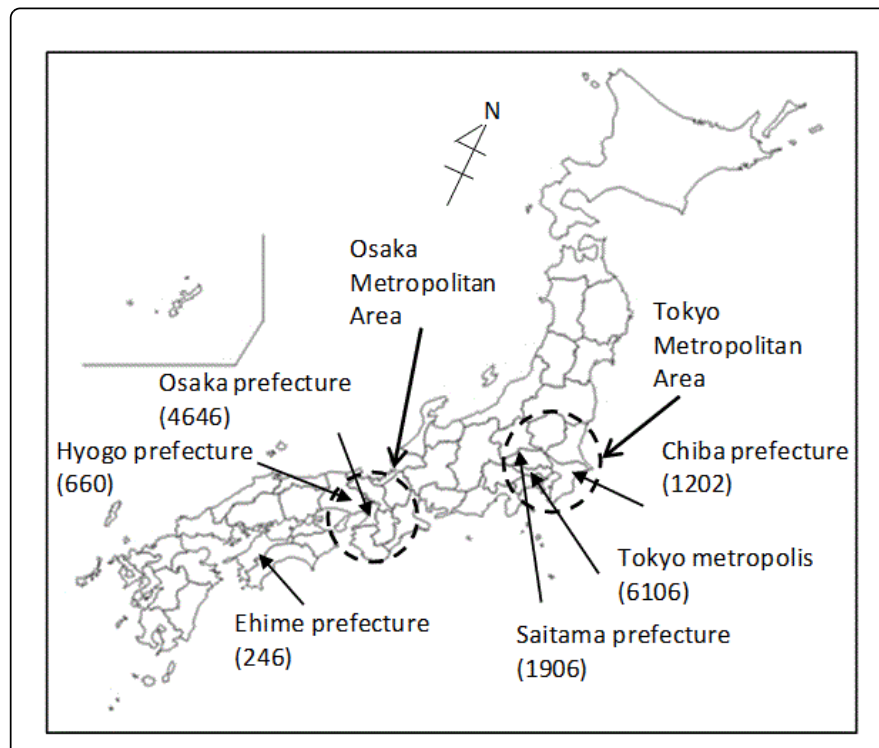

Figure 1: Characteristics of survey areas.

Numbers indicate population densities (people $/ \mathrm{km}^{2}$ ), which were calculated from data by [24] and The Geospatial Information Authority of Japan [25].

\section{Ethics statement}

The study was approved by the Ethics Committee of Chiba University. We explained our research to the educational committees of Chiba, Hyogo, Ehime and Saitama prefectures 1 and of the cities, as well as to the school principals, the head of the Yogo teacher association, and the Yogo teachers through both written and oral descriptions. All participants gave their written informed consent. After these individuals had a sufficient understanding of our project, we conducted the survey. The questionnaire was anonymous and responses were kept in lockers so the identities of the respondents would not be revealed. Moreover, the questionnaire clearly stated that responding to the questionnaire was voluntary. 
Citation: Seike K, Nakazato M, Hanazawa H, Ohtani T, Niitsu T, et al. (2016) Questionnaire Survey for Assessing the Present Condition of Children with Eating Disorders in Japanese Schools. J Health Edu Res Dev 4: 163. doi:10.4172/2380-5439.1000163

Page 3 of 7

\section{Study procedures}

The questionnaire used was developed by an early detection working group committee in Japan, and was made up of sections asking about the attributes of Yogo teachers, the features of their schools, and their experience encountering ED students, as well as a free description opportunity for the respondents and an explanation of DSM-5.

The attribute section asked about the age, gender, nurse experience, years of experience as a Yogo teacher and school type (elementary/ junior high/senior high/special needs school) of the Yogo teachers. The section on the features of the school asked about the gender type (boys'/girls'/coeducational school), the number of students, and the location of the school she/he worked at. The section on the respondent's knowledge of each ED type asked about the amount of the Yogo teacher's knowledge using a four-point scale (know well/know roughly/do not know much/do not know completely). The meeting rate section asked if the respondent had met ED students 1 by ED type (yes/no). The free description section was a section in which the respondent could freely write impressions or requests regarding the survey. The explanation of DSM-5 described each ED type based on the DSM-5 diagnosis criteria; this section was added as not all Yogo teachers were familiar with these new criteria. In Chiba prefecture, the questionnaires were distributed to Yogo teachers during a Yogo teacher seminar. In the other prefectures, they were mailed to elementary/ junior high/senior high/special needs schools and collected by mail. The results for the four prefectures were combined, and two kinds of analyses were conducted to fulfill our objectives.

The proportions of Yogo teachers who had met ED students (encounter rate) were determined by ED type.

Logistic regression analyses were performed with location, school type, number of students, years of experience as a Yogo teacher, nurse experience and knowledge of ED as explanatory variables and experience of encountering ED students for each ED type (yes/no) as a response variable.

Note that the total number of responses includes missing values. The statistical analysis software SPSS Ver. 21.0 (IBM, Tokyo, Japan) was used for the analyses.

\section{Results}

\section{Demographics of participants}

The questionnaire surveys were conducted in 2015. First, for Chiba prefecture, a survey of 1272 Yogo teachers was done at a Chiba prefecture Yogo teacher seminar in January. For the other prefectures, questionnaires were sent to schools (614 schools in Hyogo in February, 492 schools in Ehime in February, and 1301 schools in Saitama in June).

For Chiba, 661 responses were obtained (the effective response rate was 52.0\%). For Hyogo, 358 responses were received (58.3\%). Ehime had 362 responses $(73.6 \%)$ and Saitama had 503 (38.7\%). Combining these, the total sample size was 1886 .

The test power analysis software G*POWER was used to verify the appropriateness of this sample size. By assuming the test method to be two-sided, the distribution to be normal, the significance level to be 0.05 , the test power to be 0.80 , the odds ratio to be 1.3 in logistic regression analysis, the required sample size was calculated to be 721
[26]. Moreover, the previous surveys on Yogo teachers reported sample sizes of 150 [11] and 391 [13]. Therefore we judged our sample size to be large enough.

Tables 1 and 2 show the basic statistics regarding the attributes of Yogo teachers and their amount of ED knowledge. More than half $(61.7 \%)$ of the Yogo teachers worked in urban areas, and about $20 \%$ worked in semi-urban or rural areas. More than half $(56.0 \%)$ of the Yogo teachers worked at elementary schools, $28.6 \%$ at junior high schools, $11.1 \%$ at senior high schools, and $4.3 \%$ at special needs schools. A total of $26.3 \%$ of the schools had $201-400$ students, $20.5 \%$ had 401-600, and 18.2\% had 61-200. About half (53.7\%) of Yogo teachers had 20 years or more of 1 experience. Most (92.0\%) of them did 2 not have nurse experience. Most of them reported that they "know roughly" about AN, BN and BED 3 (70.7\%, 69.9\% and 55.5\% respectively), while most reported that they "do not know well" about 4 ARFID and Others (58.8\% and 58.9\%, respectively).

\begin{tabular}{|c|c|c|c|}
\hline & & $\mathbf{n}$ & Effective \% \\
\hline \multirow{3}{*}{ Location } & Rural & 1164 & 61.7 \\
\hline & Urban & 358 & 19.0 \\
\hline & Semi-urban & 364 & 19.3 \\
\hline \multirow{4}{*}{ School Type } & Elementary school & 1037 & 56.0 \\
\hline & Junior high school & 529 & 28.6 \\
\hline & Senior high school & 206 & 11.1 \\
\hline & Special needs school & 80 & 4.3 \\
\hline \multirow{7}{*}{$\begin{array}{l}\text { Number } \\
\text { Students }\end{array}$} & $1-60$ & 160 & 8.7 \\
\hline & $61-200$ & 333 & 18.2 \\
\hline & $201-400$ & 481 & 26.3 \\
\hline & $401-600$ & 375 & 20.5 \\
\hline & $601-800$ & 236 & 12.9 \\
\hline & $801-1000$ & 193 & 10.5 \\
\hline & $1001+$ & 54 & 2.9 \\
\hline \multirow{4}{*}{$\begin{array}{l}\text { Years of } \\
\text { Experience }\end{array}$} & $1-5$ & 335 & 18.0 \\
\hline & $6-10$ & 227 & 12.2 \\
\hline & $11-20$ & 299 & 16.1 \\
\hline & $20-38$ & 999 & 53.7 \\
\hline \multirow{2}{*}{$\begin{array}{l}\text { Nursing } \\
\text { Experience }\end{array}$} & Experienced & 149 & 8.0 \\
\hline & Not experienced & 1718 & 92.0 \\
\hline
\end{tabular}

Table 1: Attributes of Yogo teachers ( $n=1886)$.

\section{Statistical analysis 1}

The results of the four prefecture surveys were combined, and the encounter rates (the proportions of Yogo teachers who had met ED students) by ED type was calculated to be: AN $(45.1 \%)>\mathrm{BN}$ $(14.5 \%)>$ ARFID $(13.0 \%)>$ BED $(7.8 \%)>$ others $(5.4 \%)$ (Figure 2 and Table 3). 
Citation: Seike K, Nakazato M, Hanazawa H, Ohtani T, Niitsu T, et al. (2016) Questionnaire Survey for Assessing the Present Condition of Children with Eating Disorders in Japanese Schools. J Health Edu Res Dev 4: 163. doi:10.4172/2380-5439.1000163

Page 4 of 7

\begin{tabular}{|l|l|l|l|l|l|l|l|l|l|l|}
\hline & \multicolumn{2}{l}{ AN } & \multicolumn{2}{l}{ BN } & \multicolumn{2}{l|}{ BED } & \multicolumn{2}{l|}{ ARFID } & \multicolumn{2}{l|}{ Others } \\
\hline Amount of Knowledge & $\mathrm{n}$ & $\%$ & $\mathrm{n}$ & $\%$ & $\mathrm{n}$ & $\%$ & $\mathrm{n}$ & $\%$ & $\mathrm{n}$ & $\%$ \\
\hline Know well & 206 & 15.0 & 139 & 10.2 & 75 & 5.5 & 26 & 1.9 & 11 & 1.0 \\
\hline Know roughly & 968 & 70.7 & 955 & 69.9 & 755 & 55.5 & 325 & 23.9 & 165 & 15.0 \\
\hline Do not know well & 184 & 13.4 & 261 & 19.1 & 502 & 36.9 & 800 & 58.8 & 647 & 58.9 \\
\hline Do not know completely & 11 & 0.8 & 12 & 0.9 & 28 & 2.1 & 209 & 15.4 & 275 & 25.0 \\
\hline Missing & 517 & - & 519 & - & 526 & - & 526 & - & 788 & - \\
\hline
\end{tabular}

Table 2: Amount of ED knowledge of Yogo teachers ( $n=1886)$.

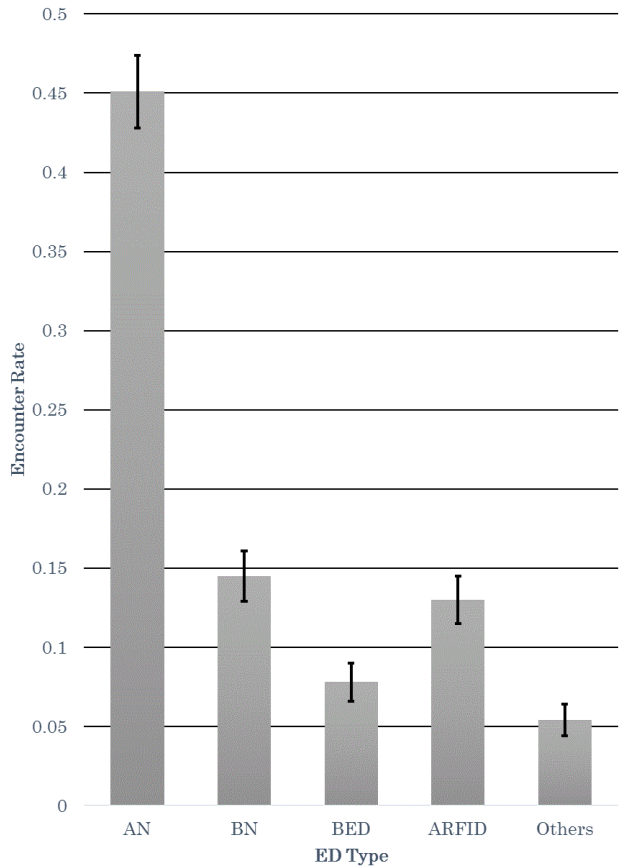

Figure 2: Encounter rates of Yogo teachers for each ED type $(95 \% \mathrm{CI})$.

\begin{tabular}{|l|l|l|}
\hline ED Type & $n$ & Encounter rate $(95 \% \mathrm{Cl})$ \\
\hline AN & 850 & $0.451(0.428-0.473)$ \\
\hline BN & 274 & $0.145(0.129-0.161)$ \\
\hline BED & 148 & $0.078(0.066-0.091)$ \\
\hline ARFID & 246 & $0.130(0.115-0.146)$ \\
\hline Others & 102 & $0.054(0.044-0.064)$ \\
\hline
\end{tabular}

Table 3: Encounter rates of Yogo teachers for each ED type. N=1886, $n=$ number of Yogo teachers met that ED type students.

\section{Statistical analysis 2}

Table 4 shows the results of the logistic analyses, which were used to verify the factors affecting the encounter rate. The significant factors for AN were location $(\mathrm{OR}=2.44 \sim 3.46)$, school type $(\mathrm{OR}=2.40 \sim 6.50)$, number of students $(\mathrm{OR}=1.001)$, years of experience $(\mathrm{OR}=1.06)$, and knowledge of $\mathrm{AN}(\mathrm{OR}=3.11)$. Those for $\mathrm{BN}$ were school type $(\mathrm{OR}=3.48 \sim 13.63)$, years of experience $(\mathrm{OR}=1.04)$, and knowledge of $\mathrm{BN}(\mathrm{OR}=2.84)$. Those for BED were location $(\mathrm{OR}=2.72)$, school type $(\mathrm{OR}=3.38 \sim 16.12)$, years of experience $(\mathrm{OR}=1.05)$, and knowledge of $\mathrm{BED}(\mathrm{OR}=3.78)$. Those for ARFID were location ( $\mathrm{OR}=1.82 \sim 1.96)$, years of experience $(\mathrm{OR}=1.03)$, and knowledge of ARFID ( $O R=94.57)$. Those for others were school type $(\mathrm{OR}=8.46)$, years of experience $(\mathrm{OR}=1.03)$, and knowledge of others $(\mathrm{OR}=4.01)$.

\begin{tabular}{|c|c|c|c|c|c|c|c|c|c|c|c|}
\hline \multirow{3}{*}{ Factor } & \multirow{3}{*}{ Level } & \multicolumn{2}{|c|}{ AN $(n=850)$} & \multicolumn{2}{|l|}{$\mathrm{BN}(\mathrm{n}=274)$} & \multicolumn{2}{|c|}{ BED $(n=148)$} & \multicolumn{2}{|c|}{ ARFID $(n=246)$} & \multicolumn{2}{|c|}{ Others $(n=102)$} \\
\hline & & $\mathbf{n}_{0} / \mathbf{n}_{1}$ & & $\mathbf{n}_{0} / \mathbf{n}_{1}$ & & $\mathbf{n}_{0} / \mathbf{n}_{1}$ & & $\mathbf{n}_{0} / \mathbf{n}_{1}$ & & $\mathbf{n}_{0} / \mathbf{n}_{1}$ & \\
\hline & & $(\%)$ & & $(\%)$ & & $(\%)$ & & $(\%)$ & & $(\%)$ & \\
\hline \multirow{3}{*}{ Location } & Rural & $\begin{array}{l}113 / 344 \\
(32.8 \%)\end{array}$ & 1.00 & $\begin{array}{l}50 / 322 \\
(15.5 \%)\end{array}$ & 1.00 & $\begin{array}{l}19 / 296 \\
(6.4 \%)\end{array}$ & 1.00 & $\begin{array}{l}36 / 294 \\
(12.2 \%)\end{array}$ & 1.00 & $\begin{array}{l}15 / 264 \\
(5.7 \%)\end{array}$ & 1.00 \\
\hline & Urban & $\begin{array}{l}533 / 1073 \\
(49.7 \%)\end{array}$ & $3.46^{\star * *}$ & $\begin{array}{l}142 / 949 \\
(15.0 \%)\end{array}$ & 1.32 & $\begin{array}{l}88 / 901 \\
(9.8 \%)\end{array}$ & $2.72^{\star *}$ & $\begin{array}{l}156 / 845 \\
(18.5 \%)\end{array}$ & $1.82^{*}$ & $\begin{array}{l}61 / 703 \\
(8.7 \%)\end{array}$ & 1.81 \\
\hline & Semi-urban & $\begin{array}{l}204 / 338 \\
(60.4 \%)\end{array}$ & $2.44^{\star \star *}$ & $\begin{array}{l}82 / 291 \\
(28.2 \%)\end{array}$ & 1.05 & $\begin{array}{l}41 / 253 \\
(16.2 \%)\end{array}$ & 1.40 & $\begin{array}{l}54 / 239 \\
(22.6 \%)\end{array}$ & $1.96^{*}$ & $\begin{array}{l}26 / 213 \\
(12.2 \%)\end{array}$ & 1.63 \\
\hline School Type & $\begin{array}{l}\text { Elementary } \\
\text { school }\end{array}$ & $\begin{array}{l}309 / 964 \\
(32.1 \%)\end{array}$ & 1.00 & $65 / 911(7.1 \%)$ & 1.00 & $\begin{array}{l}39 / 870 \\
(4.5 \%)\end{array}$ & 1.00 & $\begin{array}{l}130 / 844 \\
(15.4 \%)\end{array}$ & 1.00 & $\begin{array}{l}45 / 722 \\
(6.2 \%)\end{array}$ & 1.00 \\
\hline
\end{tabular}


Citation: Seike K, Nakazato M, Hanazawa H, Ohtani T, Niitsu T, et al. (2016) Questionnaire Survey for Assessing the Present Condition of Children with Eating Disorders in Japanese Schools. J Health Edu Res Dev 4: 163. doi:10.4172/2380-5439.1000163

Page 5 of 7

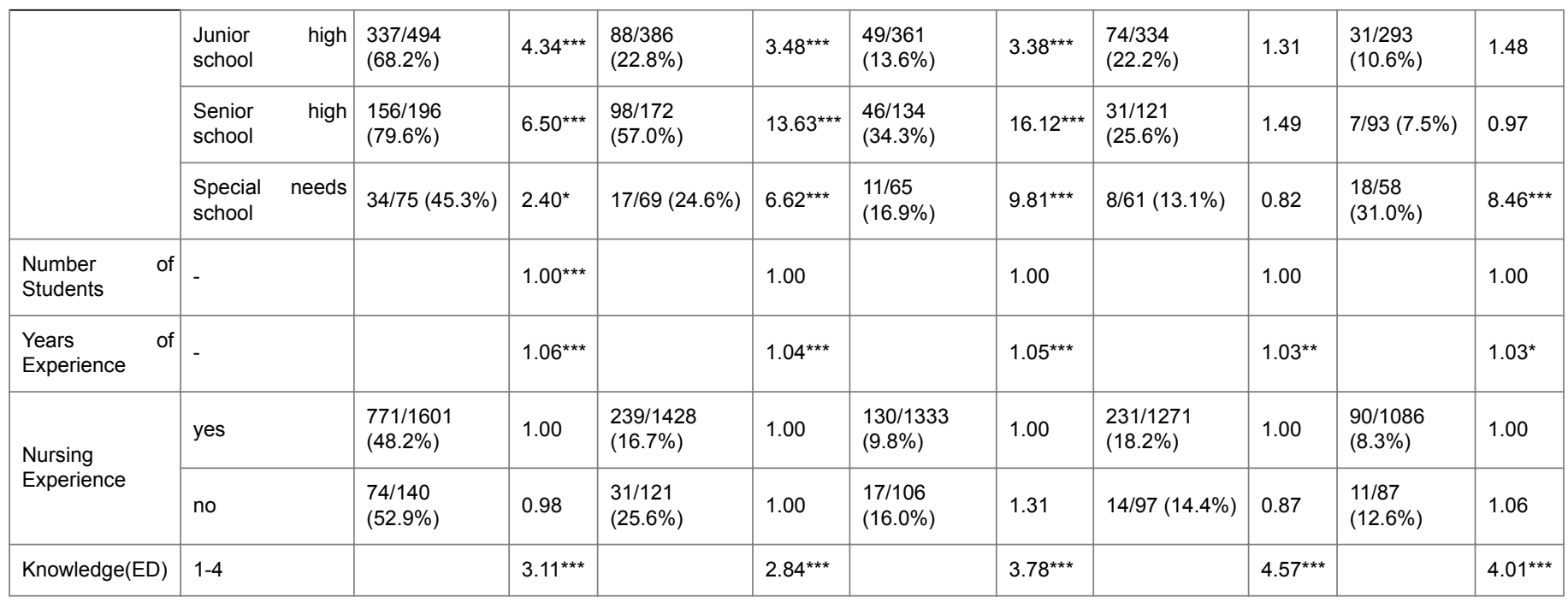

Table 4: Factors affecting encounter rate (By ED type). ${ }^{*} \mathrm{p}<0.05,{ }^{*} \mathrm{p}<0.01,{ }^{* *} \mathrm{p}<0.001$. Abbreviation: OR Odds ratio. $\mathrm{n}_{0} / \mathrm{n}_{1}=$ number of Yogo teachers met with $\mathrm{ED} /$ number of Yogo teachers=prevalence rate.

\section{Discussion}

In this study, to improve the way Yogo teachers are supported in their early detection/support of ED students, the encounter rates of EDs in a wide area of Japan were 1 calculated, and the factors that could affect those rates were examined. Let us discuss the findings in this section.

\section{Statistical analysis 1}

The order of the encounter rates for all four school types combined was $\mathrm{AN}>\mathrm{BN}>\mathrm{ARFID}>\mathrm{BED}>$ Others. Therefore, the order of the prevalence rates for seven-to 18-year-old students (in elementary/ junior high/senior high/special needs schools) was believed to be the same (Note that the order of BN and ARFID might be reversed since their confidence intervals overlapped (BN $[0.129,0.161]$, ARFID $[0.115,0.146])$. In that case, the order would be 9 AN $>$ ARFID $>$ BN $>$ BED $>$ Others).

Let us compare our results with those of surveys done outside Japan. In Ref. [21] American students aged 13 to 18 were interviewed face to face, and the order of prevalence rates was found to be BED $>B N>A N$. An English medical institute surveyed children aged 10 to 19, and the order was found to be EDNOS>AN>BN (EDNOS: Eating Disorder Not Otherwise Specified) [17]. It was reported in a number of previous studies $[4,17,19,27]$ that the onset rates of EDNOS and BED in western Europe had increased those years, while those of $\mathrm{AN}$ and $\mathrm{BN}$ in the United States and Europe had been constant or decreased since 1970 $[4,17,19,27]$.

On the other hand, a survey of Yogo teachers [13] regarding high school girl students found the order of prevalence rates to be AN $>$ EDNOS $>$ BN. Although the survey methods of these studies were different from ours and we cannot definitively draw any 1 conclusions, AN seemed to be the most prevalent in Japan. Thus, it could be effective to support AN in Japan.

\section{Statistical analysis 2}

The first finding was that the factors affecting the encounter rates for all ED types were years of experience and knowledge of ED. The OR of years of experience ranged from 1.03-1.06, which meant that the rate increased 1.03 to 1.06 times as the years of experience increased by one year. Although this result can be interpreted as "Yogo teachers enhance their skill in finding ED students as their experience increases," a simpler explanation is also possible, such as "the probability of encountering ED students increase as Yogo teachers work longer." Actually, a survey of Yogo teachers who had worked at senior high schools for more than 10 years reported that the more their years of experience increased, the more various types of EDs they encountered [28].

Secondly, the relatively high ORs (2.84-4.57) implied that the amount of knowledge contributed to the detection of ED students. It was also reported [29] that the proportion of emaciation (extreme thinness) decreased after Yogo teachers were supplied with training on ED prevention. These facts imply that it is necessary to offer ED training to improve the early detection/support of ED students in school.

In particular, our results showed that the ORs of ARFID and Others were over four. For ARFID, the ORs of all of the school types were not significant, which meant that the encounter rate of all school types did not differ much, and coincided with the studies reporting 1 that ARFID had been spread among pre-puberty children as well as very young children $[30,31]$. Thus, it can be concluded that it is necessary to educate Yogo teachers about ED in all school types. On the other hand, for others, only the OR of special needs school was significant. Some studies reported cases in which pica- and rumination-related obstacles (which were included in Others) co-existed with developmental disorders $[32,33]$. As special needs schools are schools for educating children with disorders, it made sense that the encounter rate for Others was high in that school type. Thus, it can be inferred that it would be effective to support Yogo teachers at special needs schools in the early detection/support of others students. 
Thirdly, the factor that did NOT affect the encounter rate was "nurse experience." One survey [34] of Yogo teachers with and without nurse licenses reported that personal effort contributed to the gathering and learning of ED information for both groups of teachers. These findings imply that nursing experience is not required to be successful in the early detection/support of ED students in school.

For AN, BED and ARFID, the OR of urban schools ranged from 1.82-3.46, which meant that the encounter rates were higher in urban/ semi-urban areas than in rural areas. This result was different from those of previous studies showing that the prevalence rates of urban and rural areas were almost the same [9,13,21,35-37]. The use of criteria based on DSM-5 rather than DSM-IV, as was done in the previous studies, might explain this discrepancy. For example, there could have been a considerable number of students with AN, BED or ARFID who could not be classified into the corresponding categories because of the strictness of the classification criteria of DSM-IV. But since our criteria were based on DSM-5, such students were classified correctly, making our encounter rates higher.

For school type, the ORs of all ED types except ARFID were significant. The ORs of senior high schools (with students aged from 15 to 18 ) were high (6.50-16.12) for AN, BN and BED (the OR of BN and BED were over 10), which coincided with the previous studies. An English survey [17] reported that the prevalence rates of 15- to 19year-old children were higher than those of 10- to 14-year-old children for AN, BN and EDNOS. An American survey [21] also reported that those of 15-to 16- and 17- to 18-year-old children were higher than that of 13- to 14-year-old children for BN. These findings imply that it is necessary to support $\mathrm{BN}$ or $\mathrm{BED}$ in senior high schools. Compared with this, the encounter rates in junior high schools were lower, but still significant (3.38-4.34). In particular, the OR of AN was high at 4.34 , which implies that we should support AN beginning in junior high school.

For the number of students, only the OR of AN was significant at 1.001, which means that Yogo teachers at larger schools were more likely to encounter AN students. Generally speaking, it should be more likely to encounter various types of ED students as the number of students increase. However, our results indicated that the number of students was not a significant predictor 1 for any of the ED types except AN. The difference in the sample sizes may explain this, since the sample size of AN (850) was much bigger than those of ARFID and Others $(246,102)$. The fact that the ORs of these three types were the same (1.001) also supports this explanation. (Note that the larger the sample size becomes, the more likely it is that the OR becomes significant.). These findings imply that it would be effective to offer ED knowledge mainly to Yogo teachers at school types with high encounter rates in order to enhance the early detection/support of ED students.

\section{Limitations and Recommendations}

In our survey, a questionnaire was distributed by hand at a seminar hall and by mail. This difference might lead to a difference in the degree of self-exposure to the questionnaire. Therefore the survey methods should be unified in the future. In addition, that we surveyed the encounter rate and not the prevalence rate was also a limitation. That is, what we obtained was "the proportion of Yogo teachers who had met EDs" and NOT "the proportion of ED students." For example, there exist students with EDs who cannot be detected by Yogo teachers because the teachers do not have sufficient knowledge of EDs or the students avoid visiting the offices of the Yogo teachers. In these cases, the encounter rate differs from the prevalence rate.

Since our ultimate objective was to support Yogo teachers, we considered the subjective encounter rates to be more suitable than an objective prevalence rate. However, the prevalence rate is also useful information, and should be included in a future study by asking students directly if they have EDs. In that case, information such as the age and gender of students should also be obtained, as it could contribute to better support for Yogo teachers in the early detection/ support of ED students.

In addition, our sample might be biased, as most of the surveys were collected in urban areas. We may need to gather samples equally from urban/semi-urban/rural areas in a future study.

\section{Conclusion}

In this study, a wide-area questionnaire survey was administered to Yogo teachers at elementary/junior high/senior high/special needs schools in Japan regarding their rates of encountering ED students by ED type (based on DSM-5). The encounter rates were then calculated, and the factors affecting the encounter rate were examined based on the survey results. The results showed the order of encountering rates to be $\mathrm{AN}>\mathrm{BN}>\mathrm{ARFID}>\mathrm{BED}>$ Others for students aged seven to 18 (elementary/junior high/senior high/special needs schools). As AN had a significantly higher rate than the rest, it was implied that supporting AN would be effective. One factor affecting the encounter rates of all ED types was ED knowledge. Moreover, Yogo teachers at senior high schools were most likely to encounter students with AN, $\mathrm{BN}$, or BED, and those at special needs schools were most likely to encounter 1 students with Others. These findings imply that in order to detect and support ED students early, it is necessary to offer knowledge regarding the corresponding $\mathrm{ED}$ type to Yogo teachers at the corresponding school type.

\section{Competing Interests}

The authors declare that they have no competing interests.

\section{Authors' Contributions}

KS, MN, ST, RS, and KK conceived and designed this study. All authors collected and collated the data. $\mathrm{KS}, \mathrm{MN}, \mathrm{HH}$, and TO carried out the study in Chiba. ST and SI carried out the study in Hyogo. RS, AA, and RO carried out the study in Saitama. KK and FH carried out the study in Ehime. KS, SI, AA, RO and FH analyzed the data. KS, MN, $\mathrm{HH}, \mathrm{TO}, \mathrm{ST}$, and RS interpreted the findings. KS prepared the manuscript, and $\mathrm{MN}, \mathrm{HH}, \mathrm{TO}, \mathrm{ST}$, and RS reviewed the draft and final manuscript versions. All authors read and approved the final manuscript.

\section{Acknowledgments}

We are grateful for the assistance of the Yogo teachers. We also thank Teruko Ikuno, Aya Nishizono-Maher, Tetsuya Ando, Yuki Matsumoto, Eiji Shimizu and Masaomi Iyo for their assistance. This study was supported by the Japanese Ministry of Health, Labor and Welfare (research on medical treatment system of ED). 
Citation: Seike K, Nakazato M, Hanazawa H, Ohtani T, Niitsu T, et al. (2016) Questionnaire Survey for Assessing the Present Condition of Children with Eating Disorders in Japanese Schools. J Health Edu Res Dev 4: 163. doi:10.4172/2380-5439.1000163

Page 7 of 7

\section{References}

1. Nozoe S, Tashiyama K, Nagai N, Tsutsui J, Takii M, et al. (2005) A problem and support of the patients with eating disorders who becomes youth, and becomes protraction. Japanese Journal of Psychosomatic Medicine 45: 217-223.

2. Sugiyama E, Yokoyama S (2015) The epidemiologic survey of eating disorders in students in Nagano prefecture, Japan obtained by questionnaires to Yogo teachers. Shinshu Journal of Public Health 9: 73-81.

3. Haruki S (2012) Clinical study of eating disorders in preadolescent females. Journal of Japanese Society of Psychosomatic Pediatrics 21: 161-165.

4. Nakai Y (2015) Epidemiology of eating disorders. Brain 18: 153-157.

5. Eating disorders (2015) Ministry of Health, Labor and Welfare. Japan.

6. Mitsui T (2011) Early detection and early support of the students with eating disorder by Yogo teachers. Kobe Shinwa Women's University study selection of treatises 44: 89-98.

7. Hotta M, Horikawa R, Mabe H, Yokoyama S, Sugiyama E, et al. (2015) Epidemiology of anorexia nervosa in Japanese adolescents. Biopsychosoc Med 9: 17.

8. Knightsmith P, Treasure J, Schmidt U (2013) Spotting and supporting eating disorders in school: recommendations from school staff. Health Educ Res 28: 1004-1013.

9. Komaki G, Kachi Y (2005) Eight prefecture survey of Yogo teachers inquiring about the risk factors, early detection methods and intervention for disordered eating among Japanese teenagers. Japanese Journal of Psychosomatic Medicine 45: 707-718.

10. Mitsui T, Nomura K, Suzuki T, Ikuno T (2009) The present conditions and the problem of early detection and early support of eating disorder in the school. Japanese Journal of Psychosomatic Medicine 49: 659.

11. Fukuda Y, Iguchi T, Koyanagi K, Kachi K, Tanaka T, et al. (2012) 2010 eating disorder questionnaire to Yogo teachers. Journal of Japanese Society of Psychosomatic Pediatrics. 21: 172-178.

12. Suzuki HM, Horikawa R, Kubo C, Ozaki N, Nakazato M, et al. (2013) Epidemiology investigation of the eating disorder. Ministry of Health, Health Labour Sciences Research Grant (Measures for Intractable Disease) The Study report pp: 39-44.

13. Suzuki HM, Ohara T, Horikawa R, Ogawa Y (2013) The epidemiology survey of the anorexia. Japanese Journal of Psychosomatic Internal Medicine 17: 81-87.

14. Yokoyama S, Sugiyama E (2014) Factual investigation of the anorexia nervosa and dietary behavior abnormality in the elementary school and the junior high school in Nagano. Shinshu Journal of Public Health 9: 48-49.

15. Karaki M, Takamiya S, Kawazoe A (2014) The survey concerning about between eating disorder and sports from the questionnaire for staff advisers of the sports club, Yogo teachers, teachers. Journal of Japanese Society of Psychosomatic Pediatrics 23: 271-278.

16. Kozuki H, Takamiya S, Kawazoe A, Karaki M, Isobe M, et al. (2015) School assistance and Yogo teacher's role for students with eating disorders -Cooperation with medical institutions based on result of questionnaire. Japanese Journal of Psychosomatic Medicine 55: 424-431.

17. Micali N, Hagberg KW, Petersen I, Treasure JL (2013) The incidence of eating disorders in the UK in 2000-2009: findings from the General Practice Research Database. BMJ Open.

18. Nicholls DE, Lynn R, Viner RM (2011) Childhood eating disorders: British national surveillance study. Br J Psychiatry 198: 295-301.
19. Allen KL, Byrne SM, Oddy WH, Crosby RD (2013) DSM-IV-TR and DSM-5 eating disorders in adolescents: prevalence, stability, and psychosocial correlates in a population-based sample of male and female adolescents. J Abnorm Psychol 122: 720-732.

20. Smink FR, van Hoeken D, Oldehinkel AJ, Hoek HW (2014) Prevalence and severity of DSM-5 eating disorders in a community cohort of adolescents. Int J Eat Disord 47: 610-619.

21. Swanson SA, Crow SJ, Le Grange D, Swendsen J, Merikangas KR (2011) Prevalence and correlates of eating disorders in adolescents. Results from the national comorbidity survey replication adolescent supplement. Arch Gen Psychiatry 68: 714-723.

22. Wada Y (2015) Eating disorders using the proposed DSM-5 criteria. Clinical Journal of Psychiatric Servises Seiwa Shoten Japan. 15: 300-305.

23. Birgegård A, Norring C, Clinton D (2012) DSM-IV versus DSM-5: implementation of proposed DSM-5 criteria in a large naturalistic database. Int J Eat Disord 45: 353-361.

24. Population Census (2014) Statistical Handbook of Japan.

25. The Geospatial Information Authority of Japan (2015) Ministry of Land, Infrastructure, Transport and Tourism, GSI, Japan.

26. Mizumoto A, Takeuchi O (2011) A manual for effect sizes and statistical testing: To handle statistical test definitely. Language school education media society pp: 47-73.

27. Nakai Y, Nin K, Teramukai S, Taniguchi A, Fukushima M, et al. (2013) Comparison of DSM-IV diagnostic criteria versus the Broad Categories for the Diagnosis of Eating Disorders scheme in a Japanese sample. Eat Behav 14: 330-335.

28. Ebisawa K (2012) A report on 33 cases of high school students eating disorders: Consideration about secondary prevention for anorexia nervosa. Japanese journal of school health 54: 412-417.

29. Takamiya S, Harigaya H, Kaji K, Ohnami Y, Sato T, et al. (2007) Educational activities of school health instructors (Yogo teachers) for the prevention of eating disorders in children. Japanese Journal of Psychosomatic Medicine 47: 213-218.

30. Kiriike N (2012) Feeding and eating disorders. Japanese Journal of Clinical Psychiatry. 41: 621-626.

31. Bryant-Waugh R (2013) Avoidant restrictive food intake disorder: an illustrative case example. Int J Eat Disord 46: 420-423.

32. Kasanuki H, Ataka Y, Baba G, Sakai Y, Suzuki T, et al. (2011) One case that was treated effectively with fluvoxamine for Pica behavior with the autism obstacle. Clinical Psychiatry 13 1: 39-41.

33. Kliebert ML, Tiger JH (2011) Direct and distal effects of noncontingent juice on rumination exhibited by a child with autism. J Appl Behav Anal 44: 955-959.

34. Hasegawa M, Matsuzaki M, Nakano K, Nakano H (2006) A study on the support of specialized medical institutions for the Yogo teachers with different educational backgrounds: With special reference to their relationships to eating disorder. Jpn J Psychosom Int Med 10: 157-161.

35. Hoek HW, Bartelds AI, Bosveld JJ, van der Graaf Y, Limpens VE, et al. (1995) Impact of urbanization on detection rates of eating disorders. Am J Psychiatry 152: 1272-1278.

36. Mitchison D, Hay P, Slewa-Younan S, Mond J (2014) The changing demographic profile of eating disorder behaviors in the community. BMC Public Health 14: 943.

37. Steinhausen HC, Jakobsen H, Helenius D, Munk-Jørgensen P, Strober M (2015) A nation-wide study of the family aggregation and risk factors in anorexia nervosa over three generations. Int J Eat Disord 48: 1-8. 